\title{
Lingüística
}

Vol. 36-2, diciembre 2020: 31-50

ISSN 2079-312X en línea

DOI: $10.5935 / 2079-312 X .20200013$

\section{O COMPONENTE CONTEXTUAL E A EXPRESSÃO DA MODALIDADE VOLITIVA EM LÍNGUA ESPANHOLA*}

\author{
EL COMPONENTE CONTEXTUAL Y LA EXPRESIÓN DE LA MODALIDAD VOLITIVA \\ EN ESPAÑOL
}

THE CONTEXTUAL COMPONENT AND THE EXPRESION OF VOLITIVE MODALITY IN SPANISH LANGUAGE

\author{
André Silva Oliveira \\ Universidade Federal do Ceará \\ andrethtzn@gmail.com \\ 0000-0003-3448-0659 \\ Nadja Paulino Pessoa Prata \\ Universidade Federal do Ceará \\ nadja.prata@gmail.com \\ 0000-0001-7861-7017 \\ Sandra Denise Gasparini Bastos \\ Universidade Estadual Paulista \\ sandra.gasparini@unesp.br \\ 0000-0001-5968-845
}

\section{Resumo}

Este trabalho objetiva analisar aspectos relativos ao Componente Contextual e sua relação com o Nível Morfossintático na instauração da modalidade volitiva em língua espanhola, com base nos discursos do Papa Francisco em viagem apostólica. Para isso, adotamos o modelo teórico da Gramática DiscursivoFuncional (GDF), de Hengeveld e Mackenzie (2008), considerando que o Componente Contextual pode influenciar na codificação morfossintática das expressões linguísticas. Com base em Connolly (2014) e em Hengeveld e Mackenzie (2014), que apresentam o contexto como uma estrutura complexa e multifuncional, propomos algumas categorias de análise relativas ao

\footnotetext{
* Este artigo está baseado em parte na dissertação de Mestrado de André Silva Oliveira, defendida em 2017 no PPGL/UFC. Para esta análise, ampliamos as duas categorias de análise propostas por Oliveira (2017) e acrescentamos duas outras, conforme indicado nos Procedimentos Metodológicos. Durante o mestrado, o autor foi bolsista do CNPq.
} 
Componente Contextual para a codificação da modalidade volitiva em língua espanhola. A análise dos dados mostra que a codificação morfossintática para a expressão da modalidade volitiva apresenta diferenciações, tendo em vista o tipo de ambiente e o tipo de ouvinte a quem o Papa Francisco direciona o seu discurso.

Palavras-chaves: Gramática Discursivo-Funcional; Componente Contextual; Modalidade Volitiva; Língua Espanhola; Papa Francisco.

\title{
Resumen
}

Este trabajo se propone analizar aspectos relativos al Componente Contextual y su relación con el nivel morfosintáctico en la instauración de la modalidad volitiva en español con base en los discursos del Papa Francisco en viajes apostólicos. Para ello, adoptamos el modelo teórico de la Gramática DiscursivoFuncional (GDF) de Hengeveld y MacKenzie (2008) considerando que el Componente Contextual puede influir en la codificación morfosintáctica de las expresiones lingüísticas. Con base en Connolly (2014) y en Hengeveld y MacKenzie (2014), que presentan al contexto como una estructura compleja y multifuncional, proponemos algunas categorías de análisis relativas al Componente Contextual para el análisis de la modalidad volitiva en español. El análisis de los datos muestra que la codificación morfosintáctica para la expresión de la modalidad volitiva presenta diferencias, teniendo en cuenta el tipo de ambiente y el tipo de oyente a quien se dirige el Papa Francisco.

Palabras-clave: Gramática Discursivo-Funcional; Componente Contextual; Modalidad Volitiva; Lengua Española; Papa Francisco.

\begin{abstract}
:
This work aims to analyze aspects related to the Contextual Component and its relationship with the Morphosyntactic Level for the expression of the volitive modality in Spanish language, based on the speeches of Pope Francis on apostolic journey. For this we adopted the theoretical model of Functional Discourse Grammar (FDG) by Hengeveld and Mackenzie (2008) considering that the Context Component can influence the morphosyntactic coding of linguistic expressions. Based on Connolly (2014) and Hengeveld and Mackenzie (2014) which present the context as a complex and multifunctional structure, we propose some categories of analysis related to the Contextual Component for the coding of the volitive modality in Spanish language. The analysis of the data shows that the morphosyntactic codification for the expression of the volitive modality presents differentiations, considering the type of environment and the type of listener to whom Pope Francisco directs his discourse.
\end{abstract}

Keywords: Functional Discourse Grammar; Contextual Component; Volitive Modality; Spanish language; Pope Francisco. 
Recebido: 08/01/2019

Aceito: $05 / 04 / 2019$

\section{Introdução}

Este trabalho ancora-se no modelo teórico da Gramática DiscursivoFuncional (GDF), proposta por Hengeveld e Mackenzie (2008), que se apresenta como uma teoria de análise hierárquica e modular e compreende quatro níveis de análise: Nível Interpessoal, destinado às representações pragmáticas, que diz respeito aos aspectos formais da unidade linguística que refletem seu papel na interação entre Falante e Ouvinte; Nível Representacional, que lida com os aspectos semânticos das unidades linguísticas; Nível Morfossintático e Nível Fonológico, responsáveis pela tarefa de codificação dessas categorias pragmáticas e semânticas. O modelo segue uma orientação top down, ou seja, parte da intenção do falante para a articulação das formas linguísticas, de maneira que decisões tomadas nos níveis superiores determinam e restringem possibilidades nos níveis inferiores.

Os quatro níveis de análise do modelo formam o Componente Gramatical, que se relaciona a um Componente Conceitual, a um Componente de Saída e a um Componente Contextual. Conforme estabelece a GDF, o Componente Contextual pode atuar, significativamente, nas operações de Formulação (Nível Interpessoal e Nível Representacional) e de Codificação (Nível Morfossintático e Nível Fonológico), que se dão no Componente Gramatical.

Segundo Hengeveld e Mackenzie (2008), o contexto pode ser qualquer parte circundante do discurso, sendo relevante para a sua produção e para os participantes (Falante e Ouvinte), configurando-se, dessa forma, como um construto possível de análise, o que é evidenciado no modelo. Os autores esclarecem que a GDF busca entender as estruturas dos enunciados com base em seu contexto discursivo; no entanto, não é da pretensão da teoria propor um modelo de análise do discurso ou oferecer uma descrição completa dos contextos discursivos. Ainda segundo Hengeveld e Mackenzie (2008), a GDF adota uma perspectiva de orientação para a produção do Falante e não uma perspectiva orientada para a interpretação feita pelo Ouvinte.

Também de uma perspectiva discursivo-funcional, Connolly (2014) concebe o contexto como algo dinâmico, já que se modifica na medida em que o discurso progride, restringindo-se ao que é relevante para os propósitos particulares da interação comunicativa. O contexto é fornecido pelas propriedades relevantes do meio em que se dá a interação verbal entre o Falante e o Ouvinte, ou seja, por tudo aquilo que envolve o discurso e que seja relevante para a produção e interpretação dos fenômenos linguísticos.

Considerando a modalidade volitiva como aquela que faz referência ao que é desejável, conforme Hengeveld (2004), e tendo em vista as considerações de Hengeveld e Mackenzie (2008, 2014) e de Connolly (2014) acerca da concepção de contexto, este trabalho objetiva analisar a interrelação entre os aspectos contextuais e a expressão da modalidade volitiva em língua espanhola, tendo como corpus discursos proferidos pelo Papa Francisco em viagem apostólica. 
Para tanto, apresentamos, inicialmente, o Componente Contextual e a sua inter-relação com os níveis do Componente Gramatical à luz dos pressupostos teóricos da Gramática Discursivo-Funcional (GDF), explicitando as razões pelas quais o modelo nos parece adequado para a descrição e análise do fenômeno em estudo.

Na sequência, descrevemos o processo de constituição e delimitação do corpus, apresentando as categorias de análise referentes ao Componente Contextual com base nos conceitos teóricos de Hengeveld e Mackenzie (2008), Connolly (2014) e Hengeveld e Mackenzie (2014) e na proposta de classificação de Oliveira (2017). Posteriormente, são analisados os aspectos relativos ao Componente Contextual que condicionam a expressão da modalidade volitiva nos dados analisados. Por fim, apresentamos as considerações finais acerca do fenômeno estudado.

\section{O Componente Contextual e sua inter-relação com o Componente Gramatical na perspectiva da GDF}

Segundo Hengeveld e Mackenzie (2008), a GDF consiste em uma teoria estrutural-funcional da linguagem, tipologicamente baseada, em que se toma o Ato Discursivo como a unidade básica de análise para alcançar adequação pragmática. Por isso, a GDF constitui-se de um Componente Gramatical, que é formado a partir de um modelo de interação verbal, em que há a inclusão de outros três componentes: (i) o Componente Conceitual; (ii) o Componente de Saída; e (iii) o Componente Contextual. Esses três componentes, ainda que não sejam de tipo gramatical, interagem de diversas formas com 0 Componente Gramatical, por meio das operações de Formulação e de Codificação.

Ainda segundo os autores, o Componente Contextual é o responsável pela descrição da forma e do conteúdo do discurso precedente, bem como daquilo que é perceptível no entorno do falante e do ouvinte no lugar em que se realiza $o$ ato discursivo, além das relações sociais às quais o falante e 0 ouvinte estão submetidos.

Hengeveld e Mackenzie (2008) esclarecem que o Componente Contextual contém dois tipos de informações essenciais, a saber: (i) as informações imediatas, que são recebidas do Componente Gramatical no que concerne a um enunciado em particular, o que é relevante para a forma que os enunciados subsequentes podem tomar ao longo do evento comunicativo; e (ii) as informações de longo prazo, ativadas no momento da interação verbal e relevantes para que se possam fazer as distinções necessárias que são exigidas na língua em questão e que influenciam, posteriormente, as operações de Formulação e de Codificação.

Segundo Connolly (2014), as características básicas do contexto na GDF podem ser resumidas em três tipos: (i) o contexto fornecido pelas propriedades relevantes do meio no qual se encontram os falantes; (ii) o contexto como uma construção subjetiva; e (iii) o contexto como uma estrutura em termos de uma hierarquia fundamental. 
Com base nessas características básicas, o autor divide o contexto em duas partes: (i) contexto discursivo, que é de natureza multimodal, podendo ser linguístico ou não linguístico; e (ii) contexto situacional, que se refere ao ambiente no qual estão imersos os participantes, podendo ser o contexto físico ou o contexto sociocultural. O autor ainda apresenta outra subdivisão do contexto, mas referente a questões cognitivas: (i) o contexto mental, que existe dentro da mente dos participantes; e (ii) o contexto extramental, que é fornecido pelo universo externo aos falantes.

Conforme Connolly (2014), o contexto é uma categoria muitas vezes denominada de cotexto, sendo delimitado pelo discurso em curso, enquanto a categoria mais ampla é denominada de intertexto, uma vez que se estende a outros tipos de discursos. Já o contexto situacional faz referência ao contexto no qual estão inseridos os participantes, sendo classificado como contexto interacional; quando faz referência à descrição da situação em que se dá o evento comunicativo, é definido como contexto descrito. O autor também chama a atenção para a possibilidade de que o contexto possa ser dividido em outros dois tipos: (i) o contexto físico, que faz referência às entidades animadas e inanimadas presentes no discurso, além de apresentar os seus atributos físicos, tais como o tempo e a localização no espaço; e (ii) o contexto sociocultural, que está relacionado aos participantes do discurso, à relação estabelecida entre eles, às propriedades referentes ao grau de (in)formalidade do evento de fala, além do propósito e do resultado da interação discursiva.

Hengeveld e Mackenzie (2014) estabelecem que o Componente Contextual deve fornecer as informações necessárias para o correto funcionamento do Componente Gramatical, em lugar de visar a uma especificação exaustiva de todas as informações que venham a desempenhar um papel significativo na interpretação das expressões linguísticas. Dessa forma, os autores pontuam que a interação entre o Componente Contextual e - Componente Gramatical deve ser vista como algo complementar, considerando que as línguas divergem na forma como o contexto influencia as expressões linguísticas a serem utilizadas no ato comunicativo.

Na proposta de Hengeveld e Mackenzie (2014), o Componente Contextual está dividido em quatro estratos, em que cada estrato corresponde a um dos níveis que compõe o Componente Gramatical. Por sua vez, cada estrato abrange um ou dois tipos de informação, podendo ser esta informação oriunda da situação ou procedente do discurso. A informação situacional é relevante nos estratos que correspondem aos níveis da operação de Formulação, que ocorrem no Nível Interpessoal (aspectos pragmáticos) e no Nível Representacional (aspectos semânticos), enquanto as informações do discurso estão disponíveis em todos os quatro estratos. Para os autores, as informações situacionais são relevantes para que se faça uma análise do contexto, já que elas oferecem uma seleção específica para o evento de fala, que, por sua vez, tem relevância para as operações de Formulação.

Segundo Hengeveld e Mackenzie (2014), as informações situacionais abrangem três dimensões distintas: (i) as indicações dos participantes no evento de fala, bem como de todas as propriedades que são significativas para 
a interação entre eles ${ }^{1}$; (ii) os aspectos do local onde o evento de fala ocorre; e (iii) a indicação do evento de fala em relação ao tempo ${ }^{2}$.

A partir das propostas de Conolly (2014) e de Hengeveld e Mackenzie (2014), apresentamos, sucintamente, algumas categorias de análise relativas ao Componente Contextual que podem ser relevantes para a análise da modalidade volitiva:

\begin{tabular}{|c|c|}
\hline \multirow{10}{*}{$\begin{array}{l}\text { Componente } \\
\text { Contextual }\end{array}$} & Exemplos de categorias de análise \\
\hline & $\begin{array}{c}\text { O tipo de entidade que integra o discurso, podendo ser animada } \\
\text { ou inanimada. }\end{array}$ \\
\hline & O tempo em que se dá o discurso (absoluto ou relativo). \\
\hline & $\begin{array}{l}\text { O tipo de ambiente onde ocorre o discurso (político, social, } \\
\text { religioso, etc.). }\end{array}$ \\
\hline & Os participantes que integram o discurso. \\
\hline & $\begin{array}{l}\text { O tipo de relações que se estabelecem entre os participantes do } \\
\text { discurso (hierárquica ou não hierárquica). }\end{array}$ \\
\hline & $\begin{array}{c}\text { O grau de formalidade ou informalidade em que se dá o } \\
\text { discurso. }\end{array}$ \\
\hline & $\begin{array}{l}\text { Os propósitos comunicativos e os resultados obtidos durante a } \\
\text { interação verbal. }\end{array}$ \\
\hline & $\begin{array}{c}\text { Os fenômenos reais (factuais) ou imaginários (não factuais) que } \\
\text { são abordados durante o discurso. }\end{array}$ \\
\hline & $\begin{array}{c}\text { As representações mentais que são feitas pelos falantes no } \\
\text { momento da interação verbal. }\end{array}$ \\
\hline
\end{tabular}

Tabela 1: Categorias de análise relativas ao Componente Contextual Fonte: Elaborado pelos autores

Hengeveld e Mackenzie (2014) postulam que o Componente Contextual não é responsável por toda a representação do discurso em curso, ficando a cargo de armazenar os aspectos relevantes em relação ao contexto no qual se dá o ato comunicativo e que irá influenciar no funcionamento do Componente Gramatical, uma vez que o Componente Contextual contém todas as informações da gramática que serão relevantes para a formação e articulação do que será enunciado pelos participantes posteriormente, além de fazer o armazenamento das informações de longo prazo.

Ainda segundo os autores, o Componente Contextual mantém os registros, não apenas dos resultados da operação de Formulação, mas também dos resultados provenientes da operação de Codificação, especialmente, no

\footnotetext{
${ }^{1}$ Segundo os autores, tais propriedades podem ser o sexo dos falantes (quando marcado por distinções gramaticais), a relação social entre eles (tipo de tratamento, formal ou informal), a presença de múltiplos comunicadores (o que é relevante para línguas que codificam as ilocuções exortativas, por exemplo), além da presença de espectadores no evento de fala.

2 De acordo com Hengeveld e Mackenzie (2014), à medida que as mudanças ocorrem no Componente Contextual, há uma consciência por parte dos participantes da passagem de tempo, o que é relevante para o estabelecimento do tempo absoluto em relação ao tempo relativo, que, por sua vez, são essenciais para os operadores e modificadores que serão aplicados, respectivamente, na camada do Episódio e/ou na camada dos Estados-de-Coisas, dentro do Nível Representacional.
} 
Nível Morfossintático, pois é possível que o falante faça referências anafóricas não só em relação às construções pragmáticas e semânticas, mas também em relação às estruturas morfossintáticas. Por isso, acreditamos que o Componente Contextual possa influenciar na marcação morfossintática da modalidade volitiva nos discursos do Papa Francisco que analisamos.

\section{Procedimentos metodológicos}

Para realizar a descrição e análise dos aspectos relativos ao Componente Contextual para a expressão da modalidade volitiva, optamos por analisar os discursos religiosos proferidos pelo Papa Francisco em espanhol durante as quatro viagens apostólicas que foram realizadas entre os anos de 2015 e 2016 a países que tinham o espanhol como língua oficial (Cuba, México, Equador, Bolívia e Paraguai) e aos Estados Unidos, país com grande concentração de nativos de língua espanhola. Os discursos selecionados integram o corpus organizado por Oliveira (2017).

Tendo em vista a intenção de analisarmos uma possível inter-relação entre os aspectos contextuais e os morfossintáticos, dividimos os discursos em dois tipos, considerando o tipo de ambiente em que foram proferidos, a saber: (i) discursos proferidos em ambientes políticos (DAP) e (ii) discursos proferidos em ambientes religiosos (DAR) ${ }^{3}$, conforme vemos na tabela 2 :

\begin{tabular}{|l|l|l|}
\hline Código & \multicolumn{1}{|c|}{ Título do Discurso, Data e País } & \multicolumn{1}{|c|}{$\begin{array}{c}\text { Número de } \\
\text { palavras }\end{array}$} \\
\hline DAP-1 & $\begin{array}{l}\text { Discurso en la ceremonia de bienvenida en el } \\
\text { South Lawn de la Casa Blanca en Washington } \\
\text { D.C. Miércoles, 23/09/2015 (Estados Unidos). }\end{array}$ & 650 palavras \\
\hline DAP-2 & $\begin{array}{l}\text { Discurso en la visita al Congreso de Estados } \\
\text { Unidos de América en Washington, D.C. Jueves, } \\
24 / 09 / 2015 \text { (Estados Unidos). }\end{array}$ & 3.400 palavras \\
\hline DAP-3 & $\begin{array}{l}\text { Discurso en la visita a la Sede de la } \\
\text { Organización de las Naciones Unidas en Nueva } \\
\text { York. Viernes, 25/09/2015 (Estados Unidos). }\end{array}$ & 3.900 palavras \\
\hline DAP-4 & $\begin{array}{l}\text { Discurso a las autoridades de Cuba: ceremonia } \\
\text { de bienvenida en la Habana. Sábado, } \\
19 / 09 / 2015 \text { (Cuba). }\end{array}$ & 780 palavras \\
\hline DAP-5 & $\begin{array}{l}\text { Discurso en el encuentro con las autoridades, } \\
\text { con la sociedad civil y con el cuerpo } \\
\text { diplomático. Sábado, 13/02/2016 (México). }\end{array}$ & 920 palavras \\
\hline DAP-6 & $\begin{array}{l}\text { Discurso del Santo Padre en la ceremonia de } \\
\text { bienvenida a Quito. Domingo, 05/07/2015 } \\
\text { (Equador). }\end{array}$ & 660 palavras \\
\hline Discurso en la ceremonia de bienvenida a La \\
Paz. Miércoles, 08/07/2015 (Bolívia).
\end{tabular}

${ }^{3}$ Cf. Oliveira (2017). 


\begin{tabular}{|c|c|c|}
\hline DAP-8 & $\begin{array}{l}\text { el cuerpo diplomático en el jardín del Palacio de } \\
\text { López. Viernes, } 10 / 07 / 2015 \text { (Paraguai). }\end{array}$ & 1.130 palavras \\
\hline DAR-1 & $\begin{array}{l}\text { Discurso en el encuentro con los obispos de los } \\
\text { Estados Unidos de América en la catedral de } \\
\text { San Mateo en Washington, D.C. Miércoles, } \\
\text { 23/09/2015 (Estados Unidos). }\end{array}$ & 3.500 palavras \\
\hline DAR-2 & $\begin{array}{l}\text { Discurso en el encuentro con las familias en la } \\
\text { catedral de Nuestra Señora de la Asunción, en } \\
\text { Santiago de Cuba. Martes, 22/09/2015 (Cuba). }\end{array}$ & 1.800 palavras \\
\hline DAR-3 & $\begin{array}{l}\text { Discurso en el encuentro con los obispos de } \\
\text { México en la Catedral. Sábado, 13/02/2016 } \\
\text { (México). }\end{array}$ & 4.400 palavras \\
\hline DAR-4 & $\begin{array}{l}\text { Discurso en el encuentro con el clero, religiosos, } \\
\text { religiosas y seminaristas en el Santuario } \\
\text { Nacional Mariano el Quinche de Quito. } \\
\text { Miércoles, 08/07/2015 (Equador). }\end{array}$ & 2.000 palavras \\
\hline DAR-5 & $\begin{array}{l}\text { Discurso en la capilla San Juan Bautista en la } \\
\text { visita a la población del Bañado Norte. } \\
\text { Domingo, 12/07/2015 (Paraguai). }\end{array}$ & 1.000 palavras \\
\hline \multicolumn{2}{|l|}{ Total } & 25.240 palavras \\
\hline
\end{tabular}

Tabela 2: Os discursos proferidos pelo Papa Francisco em suas viagens Fonte: Adaptado de Oliveira (2017: 109-110)

Considerando que a modalidade volitiva refere-se ao que é desejável, conforme Hengeveld (2004), julgamos que o tipo de discurso selecionado para a composição do nosso corpus (no caso o discurso religioso) seria favorável à manifestação de modalidade volitiva, já que o líder religioso (no caso o Papa Francisco) tenderia a expressar à comunidade religiosa católica e/ou à sociedade civil os seus desejos, suas vontades e intenções acerca daquilo que Ihe parece bom e agradável para o homem, sua relação com os demais, sua vivência em sociedade, etc.

Em relação a esse tipo de discurso, temos, com base em Silva (2015), que os discursos religiosos podem ser considerados discursos autoritários, já que se estabelece entre o líder religioso e os fiéis uma relação muito restrita, em que a voz da divindade está acima do plano humano, levando os fiéis a não questionarem a voz daquele que representa a divindade. Em outras palavras, na esfera religiosa, os fiéis teriam de concordar com a palavra da divindade transmitida por meio de seu representante, que geralmente comunica ao povo aquilo que a divindade "deseja" que seja acatado pelos fiéis, principalmente no tocante a questões de fé, conduta moral, normas sociais, etc.

Ainda de acordo com Silva (2015), o ato de persuadir os fiéis, expondoIhes aquilo que é desejado pelo "ser superior", conduz o discurso da persuasão à ação; por isso, o líder religioso precisaria criar uma rede discursiva entre a divindade e os fiéis para que, a partir desta rede discursiva, os fiéis possam agir conforme os preceitos religiosos da comunidade de fé.

Para realizar uma análise dos aspectos contextuais nos discursos do Papa Francisco, é necessário delimitar algumas categorias de análise referentes ao 
Componente Contextual na teoria da GDF. Com base em Hengeveld e Mackenzie (2008), Connolly (2014), Hengeveld e Mackenzie (2014) e Oliveira $(2017)^{4}$, propomos as categorias de análise descritas na sequência.

a. O tipo de ambiente: foram selecionados os discursos proferidos pelo Papa Francisco em ambientes estritamente políticos (Sede das Nações Unidas, Congresso, Sede do Governo, etc.) e religiosos (catedrais, igrejas, capelas, etc.);

b. O tipo de ouvinte: foram selecionados os discursos em que era possível identificar a quem os discursos eram direcionados, possibilitando uma divisão entre chefes de estado, altas autoridades e a sociedade civil (Ouvinte 1) e bispos, sacerdotes e fiéis católicos (Ouvinte 2);

c. O tipo de relação estabelecida com os ouvintes: estabelecemos uma divisão entre relação hierárquica (ao modalizar volitivamente, o Papa coloca-se como superior aos seus ouvintes) e não-hierárquica (o Papa coloca-se como igual). Para esta categoria de análise, nos baseamos no conceito de ethos, que, segundo Maingueneau (1997), é construído pelo falante na medida em que vai discursando para o ouvinte, ou seja, no âmbito da atividade discursiva, em que a imagem projetada pelo próprio falante vai se construindo dentro da instância enunciativa, mostrando-se por meio de seu discurso;

d. O tipo de fenômeno abordado no discurso: propomos uma divisão entre fenômenos factuais (localizáveis no tempo e no espaço) ou nãofactuais (localizados apenas na mente do falante).

Acreditamos que as categorias de análise propostas relacionam-se à forma como as expressões da modalidade volitiva nos discursos do Papa Francisco se apresentam, uma vez que os condicionamentos contextuais podem influenciar as escolhas linguísticas do falante. Tomando por base tais características, postulamos que os discursos religiosos pronunciados pelo Papa seriam propícios à manifestação da modalidade volitiva, como se confirmará na análise apresentada na sequência.

\section{Resultado: análise e discussão dos dados}

Nesta seção, apresentamos a descrição e análise dos aspectos relativos ao Componente Contextual que condicionam a expressão da modalidade volitiva nos discursos do Papa Francisco em língua espanhola.

\subsection{O tipo de ambiente}

\footnotetext{
4 Oliveira (2017) propõe apenas duas categorias de análise relativas ao Componente Contextual: (i) o tipo de discurso (político ou religioso); e (ii) o tipo de ouvinte. As outras duas categorias (o tipo de fenômeno abordado e o tipo de relação entre os ouvintes) representam um acréscimo a essa proposta e serão analisadas apenas de maneira qualitativa.
} 
$\mathrm{Na}$ análise dos dados, verificamos que os ambientes religiosos foram os mais propícios para uma maior ocorrência do emprego de expressões de modalidade volitiva por parte do Papa Francisco. Tal fato se explica em razão do propósito das viagens apostólicas realizadas pelo Papa Francisco, qual seja: manifestar ou reforçar para a comunidade católica aquilo que lhe parece desejável (ou desejável para a divindade que representa) em relação às questões de fé, conduta, moral, etc., o que também configura, segundo Connolly (2014), como um dos aspectos relevantes do contexto, já que os propósitos comunicativos e os resultados obtidos durante a interação verbal influenciam as operações de Formulação e de Codificação (Componente Gramatical). Vejamos a Tabela 3:

\begin{tabular}{|c|c|c|}
\hline Ambiente do Discurso & No. & \% \\
\hline Religioso & 62 & 53,0 \\
\hline Político & 55 & 47,0 \\
\hline Total & 117 & 100,0 \\
\hline
\end{tabular}

Tabela 3: Tipos de ambiente dos discursos do Papa Francisco para instauração da modalidade volitiva em língua espanhola. Fonte: Extraída de Oliveira (2017: 121)

Como vemos na Tabela 3, a frequência de modalidade volitiva em ambientes religiosos é maior do que em ambientes políticos, considerando que as viagens apostólicas realizadas pelo Papa Francisco estão mais voltadas para sua missão pastoral como Chefe da Igreja Católica e representante da Santa Sé. Entretanto, isso não impede que o Papa empregue a modalidade volitiva também em ambientes políticos, diante da possibilidade de comunicar aos chefes de estado, às altas autoridades e à sociedade civil o que lhe parece desejável. Vejamos (1) e $(2)^{5}$ :

1 Durante mi visita, voy a tener el honor de dirigirme al Congreso, donde espero, como un hermano de este País, transmitir palabras de aliento a los encargados de dirigir el futuro político de la Nación en fidelidad a sus principios fundacionales (DAP-1)

[Durante a minha visita, vou ter a honra de me dirigir ao Congresso, onde espero, como um irmão deste país, transmitir palavras de encorajamento aos encarregados de dirigir o futuro político da nação com fidelidade aos seus princípios fundadores]

2 [...] que cada una se toca la panza y yo le doy la bendición en el nombre del Padre y del Hijo y del Espíritu Santo y deseo que venga sanito, que crezca bien, que lo pueda criar lindo, acaricien al hijo que están esperando (DAR-2)

[Que cada uma toque a sua barriga e eu lhe dou a bênção em nome do Pai, do Filho e do Espírito Santo e desejo que venha saudável, que cresça bem, que possam criá-lo lindamente, acariciem o filho que estão esperando]

Em (1), temos um caso de modalidade volitiva instaurada, em ambiente político, por meio do verbo esperar, em que o Papa Francisco expressa um desejo seu (o que fica evidenciado pelo emprego da primeira pessoa do singular, espero) de que "consiga transmitir palavras de encorajamento" (evento volitivo) aos dirigentes da nação americana que estarão no Congresso.

Em (2), observamos um caso de modalidade volitiva instaurada em ambiente religioso por meio do verbo desear, em que o Papa Francisco

\footnotetext{
${ }^{5}$ Para todos os exemplos extraídos do corpus, oferecemos uma tradução de nossa autoria, com o intuito de facilitar a compreensão dos contextos de emprego da modalidade volitiva.
} 
expressa um desejo seu (identificável pelo uso da primeira pessoa do singular, deseo) de que os filhos das mulheres grávidas ali presentes possam crescer bem (evento volitivo).

Ainda em (1), a modalização volitiva tem seu valor pleno de "desejabilidade" em razão da carga semântica do verbo esperar e aquilo que ele escopa, pois sendo o escopo algo que escapa ao controle do falante (o Papa), já não seria possível prever a reação dos dirigentes da nação quando ele proferisse suas palavras de encorajamento. Em (2), a modalização volitiva tem seu valor pleno de "desejabilidade" em virtude da carga semântica do modalizador desejar e do suporte dado pela oração completiva seguida de verbo conjugado no subjuntivo (que venga, que crezca, que pueda), já que o subjuntivo é o modo verbal prototípico da modalidade volitiva em razão de seu aspecto irrealis.

Além da frequência dos tipos de modalizações volitivas para o tipo de ambiente, verificamos estatisticamente ${ }^{6}$ a inter-relação entre o Componente Contextual (o tipo de ambiente) e o Componente Gramatical (especificamente o Nível Morfossintático). A hipótese é que a codificação da modalidade volitiva no Nível Morfossintático da GDF se daria de maneiras diferentes, tendo em vista os elementos do Nível Interpessoal (posição do falante e tipo de ilocução), do Nível Representacional (fonte volitiva, alvo volitivo e os valores semânticos da modalidade volitiva) e o Componente Contextual (tipo de ambiente e de ouvinte).

As ocorrências de modalidade volitiva levantadas no corpus foram agrupadas em cinco diferentes formas de expressão: verbo auxiliar modal, verbo pleno, substantivo, adjetivo em posição predicativa e construção volitiva ${ }^{7}$. A análise dos dados mostra que o tipo de ambiente está relacionado às formas de expressão da modalidade volitiva, conforme pode ser visualizado na Tabela 4:

\begin{tabular}{|c|c|c|c|c|c|c|}
\hline \multirow[b]{2}{*}{$\begin{array}{c}\text { Tipo de } \\
\text { Ambiente }\end{array}$} & \multicolumn{5}{|c|}{ Forma de expressão } & \multirow[b]{2}{*}{ Total } \\
\hline & $\begin{array}{c}\text { Auxiliar } \\
\text { modal }\end{array}$ & $\begin{array}{l}\text { Verbo } \\
\text { pleno }\end{array}$ & Substantivo & $\begin{array}{c}\text { Adjetivo } \\
\text { (posição } \\
\text { predicativa) }\end{array}$ & $\begin{array}{c}\text { Construção } \\
\text { volitiva }\end{array}$ & \\
\hline \multirow[t]{2}{*}{ Religioso } & 19 & 11 & 02 & 04 & 26 & 62 \\
\hline & $16,2 \%$ & $9,4 \%$ & $1,7 \%$ & $3,4 \%$ & $22,2 \%$ & $53,0 \%$ \\
\hline \multirow[t]{2}{*}{ Político } & 10 & 23 & 07 & 01 & 14 & 55 \\
\hline & $8,5 \%$ & $19,7 \%$ & $6,0 \%$ & $0,9 \%$ & $12,0 \%$ & $47,0 \%$ \\
\hline \multirow[t]{2}{*}{ Total } & 29 & 34 & 09 & 05 & 40 & 117 \\
\hline & $24,8 \%$ & $29,1 \%$ & $7,7 \%$ & $4,3 \%$ & $34,2 \%$ & $100 \%$ \\
\hline
\end{tabular}

Tabela 4: Inter-relação entre o tipo de ambiente e a forma de expressão da modalidade volitiva em língua espanhola. Fonte: Extraída de Oliveira (2017: 211)

\footnotetext{
${ }^{6}$ A análise da frequência foi feita com o apoio do Programa SPSS (Statistical Package for Social Science) e do teste do Qui-quadrado.

7 Optamos por atribuir o termo construção volitiva às construções introduzidas pela partícula que seguidas de verbo no subjuntivo.
} 
Os dados mostram que nos ambientes políticos houve preferência pelo emprego de verbos plenos para a instauração da modalidade volitiva, enquanto em ambientes religiosos houve maior incidência de construções volitivas. Segundo Oliveira (2017), em ambientes políticos, o emprego de verbos plenos se justifica em razão da carga semântica que o verbo traz ao modalizar o discurso volitivamente, já que possui um núcleo de significação verbal em si mesmo e assevera a desejabilidade expressa ao Ouvinte 1 acerca de assuntos geralmente políticos.

Nos ambientes religiosos, a maior incidência de construções volitivas pode ser explicada com base em Grande Alija (2016). Segundo o autor, em razão do caráter desiderativo-apelativo do modo subjuntivo em que se conjugam os verbos suportes nas construções volitivas, estas passam a funcionar como uma espécie de rogo ou súplica mais atenuada do que é desejado pelo falante, movendo o Ouvinte 2 a performatizar o evento volitivo expresso. Vejamos (3) e (4):

3 Confío también que la Conferencia de París sobre el cambio climático logre acuerdos fundamentales y eficaces (DAP-3)

[Confio também que a Conferência de Paris sobre as mudanças climáticas consiga acordos fundamentais e eficazes]

4 Por favor, que nuestra pastoral sea gratuita y es tan feo cuando uno va perdiendo este sentido de la gratuidad. (DAR-4)

[Por favor, que nossa pastoral seja gratuita e é tão feio quando se vai perdendo este sentido da gratuidade].

Em (3), verificamos que o Papa Francisco emprega o modalizador volitivo confiar (no sentido de ter esperança), para expressar um desejo seu (confío) de que "a Conferência para os assuntos climáticos consiga acordos fundamentais e eficazes" (evento volitivo). Em (4), o Santo Padre faz uso da construção volitiva que + subjuntivo para exortar, em um ambiente religioso, os bispos e sacerdotes católicos a "realizarem sua ação pastoral de forma gratuita" (evento volitivo). Segundo Grande Alija (2016), a construção volitiva que + subjuntivo já carrega consigo toda a carga semântica apelativodesiderativa, asseverando a desejabilidade expressa pelo falante (no caso, o Papa Francisco).

\subsection{O tipo de ouvinte}

Os dados mostram que as ocorrências de modalidade volitiva foram empregadas tanto para o Ouvinte 1 (chefes de estado, altas autoridades e sociedade civil) quanto para o Ouvinte 2 (bispos, sacerdotes e fiéis católicos), como vemos na Tabela 5:

\begin{tabular}{|c|c|c|}
\hline Tipo de Ouvinte & No. & \% \\
\hline Ouvinte 2 & 61 & 52,1 \\
\hline Ouvinte 1 & 56 & 47,9 \\
\hline Total & 117 & 100,0 \\
\hline
\end{tabular}

Tabela 5: Tipos de ouvinte para instauração da modalidade volitiva nos discursos do Papa Francisco em língua espanhola. Fonte: Extraída de Oliveira (2017: 130) 
Verificamos uma maior porcentagem de modalizações volitivas direcionadas para o Ouvinte 2, o que pode ser explicado com base nos objetivos pelos quais as viagens apostólicas dos Papas da Igreja Católica são pensadas, que é de expandir a fé católica pelo mundo e a propagação dos ensinamentos doutrinários católicos.

Considerando o público a quem o Sumo Pontífice se dirige, era de se esperar uma maior incidência de instauração de modalizações volitivas para o Ouvinte 2. Nesses casos, a modalidade volitiva estaria relacionada ao que o Papa Francisco desejaria expressar em relação à conduta dos fiéis católicos e/ou dos demais líderes religiosos a ele subordinados espiritualmente (bispos, sacerdotes e religiosos). Vejamos (5) e (6):

5 Me he animado a esbozar algunas de las riquezas de su patrimonio cultural, del alma de su pueblo (DAP-2)

[Me animei a fazer um esboço de algumas das riquezas de seu patrimônio cultural, da alma de seu povo]

$6[\ldots]$ estos dos principios que dije al principio: gratuidad y memoria es el gozo y la alegría. Y es un regalo de Jesús ese y es un regalo que Él da, que É nos da si se lo pedimos y si no nos olvidamos de esas columnas de nuestra vida sacerdotal o religiosa que son el sentido de gratuidad renovado todos los días y no perder la memoria de donde nos sacaron. Yo le deseo esto. (DAR-4)

[Estes dois princípios que disse no início: gratuidade e memória é o gozo e a alegria. É um presente de Jesus e é um presente que Ele nos dá, que Ele que nos dá se pedimos e se não nos esquecemos dessas colunas da nossa vida sacerdotal ou religiosa que são o sentido de gratuidade renovado todos os dias e não perder a memória de onde viemos. Eu desejo-lhes isso]

Em (5), verificamos que o Papa Francisco instaura a modalização volitiva para o Ouvinte 1 (no caso a sociedade civil americana), por meio do modalizador volitivo animar, expressando uma desejabilidade sua (tendo em vista o emprego da primeira pessoa do singular, he animado) de "falar acerca da riqueza cultural do país ao qual visita" (evento volitivo).

Em (6), verificamos que a desejabilidade expressa tem como fonte também o próprio Papa Francisco (considerando o uso da primeira pessoa do singular, deseo), ao empregar o verbo volitivo desear para modalizar, volitivamente, o evento "Jesus presenteia o povo católico com os dons da gratuidade de serviço e o reconhecimento de suas origens", instaurando, pois, a volição sobre o Ouvinte 2 .

Observamos que não há um condicionamento entre as categorias de análise apresentadas, ou seja, o tipo de ambiente não determina o tipo de ouvinte, pois foi possível verificar o direcionamento de modalizações volitivas para ambos os tipos de ouvinte, tanto em ambiente político quanto em ambiente religioso. Conforme mostraram os dados, em ambientes políticos houve uma maior porcentagem de modalizações volitivas para o Ouvinte 1 $(46,43 \%$ do total de ocorrências) em comparação com o Ouvinte 2 (2,49\% do total de ocorrências).

Em ambientes religiosos, deu-se o contrário, já que houve uma maior porcentagem de modalizações volitivas para o Ouvinte 2 (47,54\% do total de 
ocorrências) em comparação com o Ouvinte 1 (3,57\% do total de ocorrências) ${ }^{8}$.

Analisamos, também, a inter-relação entre o Componente Contextual (especificamente, o tipo de ouvinte) e o Componente Gramatical e verificamos que apenas a forma de expressão (categoria relativa ao Nível Morfossintático) é que se inter-relaciona com o tipo de ouvinte, como podemos ver na Tabela 6:

\begin{tabular}{|c|c|c|c|c|c|c|}
\hline \multirow[b]{2}{*}{$\begin{array}{l}\text { Tipo de } \\
\text { ouvinte }\end{array}$} & \multicolumn{5}{|c|}{ Forma de expressão } & \multirow[b]{2}{*}{ Total } \\
\hline & $\begin{array}{c}\text { Auxiliar } \\
\text { modal }\end{array}$ & $\begin{array}{l}\text { Verbo } \\
\text { pleno }\end{array}$ & Substantivo & $\begin{array}{c}\text { Adjetivo } \\
\text { (posição } \\
\text { predicativa) }\end{array}$ & $\begin{array}{c}\text { Construção } \\
\text { volitiva }\end{array}$ & \\
\hline \multirow[t]{2}{*}{ Ouvinte 2} & 19 & 10 & 02 & 04 & 26 & 61 \\
\hline & $16,2 \%$ & $8,5 \%$ & $1,7 \%$ & $3,4 \%$ & $22,2 \%$ & $52,1 \%$ \\
\hline \multirow[t]{2}{*}{ Ouvinte 1} & 10 & 24 & 07 & 01 & 14 & 56 \\
\hline & $8,5 \%$ & $20,5 \%$ & $6,0 \%$ & $0,9 \%$ & $12,0 \%$ & $47,9 \%$ \\
\hline \multirow[t]{2}{*}{ Total } & 29 & 34 & 09 & 05 & 40 & 117 \\
\hline & $24,8 \%$ & $29,1 \%$ & $7,7 \%$ & $4,3 \%$ & $34,2 \%$ & $100 \%$ \\
\hline
\end{tabular}

Tabela 6: Inter-relação entre o tipo de ouvinte e a forma de expressão nos discursos do Papa Francisco em língua espanhola. Fonte: Extraída de Oliveira (2017: 213)

A Tabela 6 mostra um predomínio de verbo pleno quando o Papa Francisco instaura a modalidade volitiva para o Ouvinte 1, enquanto para o Ouvinte 2 há maior incidência de construções volitivas. O emprego de verbos plenos nas modalizações volitivas para o Ouvinte 1 deve-se à carga semântica volitiva do modalizador empregado, sinalizando para os ouvintes aquilo que o Papa deseja em relação ao que julga ser bom e agradável para as sociedades, enquanto o uso de construções volitivas para o Ouvinte 2 está relacionado ao aspecto apelativo-desiderativo, escopando, geralmente, aquilo que o Papa Francisco deseja que a comunidade católica, em especial, bispos e sacerdotes, performatize em relação ao que ele (ou a divindade que representa) julga ser correto e adequado em termos de moral e conduta. Vejamos (7) e (8):

7 [...] tratemos a los demás con la misma pasión y compasión con la que queremos ser tratados. (DAP-2)

[Tratemos aos demais com a mesma paixão e compaixão com que queremos ser tratados]

8 Hermanos, que sus corazones sean capaces de seguirlos y alcanzarlos más allá de las fronteras. (DAR-3)

[Irmãos, que seus corações sejam capazes de segui-los e de alcançá-los muito além das fronteiras].

Em (7), ao discursar para o Ouvinte 1, o Papa Francisco emprega o verbo pleno querer para instigar seu(s) ouvinte(s) a "tratar os demais da mesma forma como gostariam de ser tratados" (evento volitivo). Em (8), ao empregar a construção volitiva que + subjuntivo, o Papa exorta o Ouvinte 2,

8 As porcentagens apresentadas referem-se à totalidade das modalizações volitivas encontradas (117 ocorrências) somando-se os dois ambientes (político e religioso). 
particularmente os bispos e sacerdotes, a "apascentar o rebanho, seguindo os corações dos fiéis, até ultrapassar todas as fronteiras" (evento volitivo).

Verificamos que o Componente Contextual (tipo de ambiente onde o discurso é proferido e o tipo de ouvinte para quem o discurso se direciona) influencia a codificação morfossintática para a expressão da modalidade volitiva da seguinte maneira: (i) para o Ouvinte 1 e em ambientes políticos, a modalidade volitiva é instaurada predominantemente por meio de verbos plenos; (ii) para o Ouvinte 2 e em ambientes religiosos, o Sumo Pontífice optou por instaurar modalizações volitivas por meio de construções volitivas.

\subsection{O tipo de relação estabelecida com os ouvintes}

No que concerne ao tipo de relação estabelecida com os ouvintes, hipotetizamos que a modalidade volitiva poderia ser instaurada pelo falante considerando o tipo de ethos projetado por ele, o que nos levou a diferenciar dois tipos de relação estabelecida pelo falante com os ouvintes e marcada no discurso, hierárquica ou não-hierárquica, conforme vemos em (9) e em (10):

9 Ensanchar el corazón para dar testimonio de que Dios es grande en su amor es la sustancia de la misión del Sucesor de Pedro, Vicario de Aquel que en la cruz extendió los brazos para acoger a toda la humanidad. Que ningún miembro del Cuerpo de Cristo y de la nación americana se sienta excluido del abrazo del Papa (DAR-1)

[Engrandecer o coração para dar testemunho de que Deus é grande em seu amor é a essência da missão do Sucessor de Pedro, Vigário d'Aquele que na cruz estendeu os braços para acolher toda a humanidade. Que nenhum membro do Corpo de Cristo e da nação americana se sinta excluído do abraço do Papa]

10 Permítanme tan sólo, con la libertad del amor, que les hable como un hermano entre hermanos. No pretendo decirles lo que hay que hacer, porque todos sabemos lo que el Señor nos pide (DAR-1)

[Permitam-me apenas, com a liberdade do amor, que lhes fale como um irmão entre irmãos. Não pretendo dizer o que é preciso fazer, porque todos sabemos o que o Senhor nos pede]

Vemos que o Papa Francisco instaura modalizações volitivas por meio da construção volitiva que + subjuntivo (09) e do verbo pretender (10) sobre o Ouvinte 2 (bispos, sacerdotes e fiéis católicos), em relação ao desejo de "que todos se sintam acolhidos pelo abraço do Papa" e "da não pretensão de falarIhes sobre o que é preciso que se faça" (eventos volitivos). No entanto, comprovamos, em seus discursos, que ora o Papa Francisco projeta um ethos de autoridade, como "Vigário de Cristo e Sucessor de Pedro", sinalizando para o Ouvinte 2 a posição de superioridade (hierárquica) em que se encontra (conforme (09)), ora o Sumo Pontífice projeta um ethos mais amigável, como "um irmão entre os outros irmãos", criando uma posição de igualdade (nãohierárquica, conforme (10)).

Segundo Boaventura e Freitas (2016), nos discursos do Papa Francisco, é possível encontrar dois tipos específicos de ethos: (i) um pré-discursivo, em que a opinião que o ouvinte possui em relação ao Papa Francisco já começa antes mesmo que ele faça o pronunciamento, haja vista que esse tipo de ethos advém da memória coletiva recuperada a respeito da pessoa que ele representa; e (ii) um discursivo, que vai se construindo à medida que o Papa Francisco se pronuncia, estando, pois, relacionado à aparência que Ihe confere a fluência na língua do pronunciamento, a entonação dada ao se pronunciar 
(mais calorosa ou mais severa), a escolha das palavras, dos argumentos, etc., elementos que auxiliam o Papa Francisco no tipo de ethos que ele deseja projetar.

Resumidamente, podemos dizer que o Ouvinte 2 já apresenta em sua memória um ethos pré-discursivo em relação ao Papa Francisco, vendo-o como a "Autoridade Máxima da Igreja Católica", "Vigário de Cristo", "Sucessor de Pedro", "Representante de Cristo", etc., cabendo ao Papa reforçar esse ethos em seus discursos, como vemos em (09), ou desconstruir esse ethos prédiscursivo, passando a projetar um ethos mais amigável, que viria a ser o novo ethos projetado, ou seja, o ethos discursivo, como mostrado em (10).

Os dados mostram também algumas ocorrências de ethos mais amigável (relação não-hierárquica) em discursos proferidos para o Ouvinte 1. Vejamos (11):

11 Amigos todos, comienzo con ilusión y esperanza los días que tenemos por delante. En Ecuador está el punto más cercano al espacio exterior: es el Chimborazo, llamado por esto al lugar 'más cercano al sol', a la luna y a las estrellas. Desde aquí quiero abrazar al Ecuador entero. Que desde la cima del Chimborazo, hasta las Costas del Pacífico; desde la Selva Amazónica, hasta las Islas Galápagos, nunca pierdan la capacidad de dar gracias a Dios por lo que hizo y hace por ustedes (DAP-6)

[Amigos, começo com alegria e esperança os dias que temos pela frente. No Equador está o ponto mais próximo ao espaço exterior: é o Chimboraço, chamado assim porque é o lugar mais próximo do sol, da lua e das estrelas. Daqui quero abraçar o Equador inteiro.

Que do alto do Chimboraço até a Zona Costeira do Pacífico, da Selva Amazônica até as Ilhas Galápagos, nunca percam a capacidade de dar graças a Deus pelo que Ele fez e faz por todos vocês]

Em (11), vemos que o Papa Francisco, ao projetar um ethos mais amigável para o Ouvinte 1 , instaura a modalidade volitiva por meio da construção volitiva que + subjuntivo para expressar a desejabilidade de que "os equatorianos possam reconhecer as maravilhas que Deus tem feito por eles" (evento volitivo).

De acordo com Boaventura e Freitas (2016), ao discursar para a sociedade civil, o Papa Francisco busca conquistar adesão do público, procurando projetar um ethos que, além de inspirar uma relação de empatia entre ele e os seus ouvintes, procura criar condições para que o público possa compreendê-lo e participar do mundo particular de sua crença que está sendo engendrada por meio de seu discurso. Dessa forma, observamos, por parte do Papa, a necessidade volitiva de incorporação dos seus ouvintes em seus discursos, já que o ouvinte, na posição de intérprete, apropria-se desse ethos.

Tendo em vista os tipos de ambiente, os tipos de ouvinte e os tipos de ethos projetados pelo Sumo Pontífice nos seus discursos, foi possível também analisar o tipo de fenômeno abordado no discurso em relação às modalizações volitivas instauradas, como veremos na subseção seguinte.

\subsection{O tipo de fenômeno abordado no discurso}

Segundo Camacho e Bechara (2011), dentro do aparato teórico da Gramática Discursivo-Funcional (GDF), o Nível Representacional, relacionado aos aspectos semânticos da formulação linguística, no qual a modalidade está representada, prevê a análise de elementos como a identidade dos 
participantes e a factualidade do evento. Para que um evento seja considerado factual, é necessário que ele descreva propriedades aplicáveis no mundo real, estado-de-coisas entendidos como reais, conteúdos proposicionais verdadeiros e atos discursivos assertivos; enquanto um evento não-factual descreve propriedades que são apenas aplicáveis em um mundo abstrato, estado-decoisas entendidos como imaginários, conteúdos proposicionais não verdadeiros ou considerados apenas verdadeiros no mundo ao qual o falante tem acesso (já que só poderiam ser localizados na sua mente), e atos discursivos não assertivos.

Em relação ao tipo de fenômeno abordado nos discursos do Papa Francisco, foi possível identificar casos de modalidade volitiva relacionados à factualidade do evento volitivo apresentado (podendo ser localizado no tempo e no espaço), em que os desejos do Papa Francisco tinham alguma relação com aquilo que ele esperava que viesse a se concretizar no plano factual; e casos relacionados à não-factualidade do evento volitivo manifestado (podendo ser apenas localizado na mente do Sumo Pontífice, fruto da sua fé e de suas crenças), em que a desejabilidade expressa se referia a algo oriundo de suas crenças religiosas, podendo concretizar-se apenas para aqueles que delas compartilham, no plano não-factual. Vejamos (12) e (13):

12 La Eucaristía es la cena de la familia de Jesús, que a lo largo y ancho de la tierra se reúne para escuchar su Palabra y alimentarse con su Cuerpo. Jesús es el Pan de Vida de nuestras familias, Él quiere estar siempre presente alimentándonos con su amor, sosteniéndonos con su fe, ayudándonos a caminar con su esperanza (DAR-2)

[A Eucaristia é a ceia da família de Jesus, que de todos os cantos da Terra se reúnem para escutar sua Palavra e alimentar-se com seu Corpo. Jesus é o Pão da Vida de nossas famílias, Ele quer estar sempre nos alimentando com seu amor, sustentando-nos com sua fé, ajudando-nos a caminhar com sua esperança]

13 Terminaré mi visita a su País en Filadelfia, donde participaré en el Encuentro Mundial de las Familias. He querido que en todo este Viaje Apostólico la familia fuese un tema recurrente (DAP-2)

[Terminarei minha visita a seu país na Filadélfia, onde participarei do Encontro Mundial das Famílias. Quis que em toda essa Viagem Apostólica a família fosse um tema recorrente]

Em (12), o Papa Francisco reporta o que parece ser a desejabilidade da divindade a qual representa, no caso, Jesus Cristo, ao proferir que Ele "deseja estar alimentando as pessoas com seu amor, sustentando com a sua fé e ajudando-as a seguir pelo caminho da esperança" (evento volitivo). Vemos que - Papa Francisco instaura a modalização volitiva baseando-se nas suas crenças, por isso o fenômeno abordado no discurso está no plano não-factual (realizável apenas para aqueles que também compartilham da mesma fé), proveniente do dogma da Transubstanciação?.

Em (13), a modalidade volitiva se expressa por meio do verbo modal querer, conjugado na primeira pessoa do singular (quiero), evidenciando que a volição instaurada advém dele.

Observamos que a modalidade volitiva está relacionada a um fenômeno que está no plano factual, dado que o Papa Francisco "deseja debater acerca

\footnotetext{
${ }^{9}$ De acordo com o Catecismo da Igreja Católica (2010), o pão e o vinho consagrados durante a celebração da Santa Missa transformam-se no corpo e sangue de Cristo; por isso a Eucaristia é entendida, pelos fiéis católicos, como a presença real de Jesus Cristo entre as pessoas.
} 
da família" (evento volitivo) no Encontro Mundial das Famílias que se realizará na Filadélfia (o evento volitivo pode ser localizado no tempo e no espaço).

\section{Considerações finais}

Neste trabalho, abordamos os principais aspectos contextuais presentes na cena enunciativa do Papa Francisco ao discursar em suas viagens apostólicas. Para isso, nos baseamos no modelo teórico da Gramática Discursivo-Funcional (GDF) em relação ao Componente Contextual que, segundo Hengeveld e Mackenzie (2008), refere-se à descrição da forma e do conteúdo do discurso precedente, abarcando também o entorno no qual estão inseridos os participantes do ato comunicativo e as relações sociais que se estabelecem entre eles.

Tendo como corpus de análise os discursos do Papa Francisco proferidos em viagens apostólicas, buscamos descrever e analisar a expressão da modalidade volitiva no que diz respeito ao contexto em que se deram os discursos papais, acreditando que o Nível Morfossintático (referente à codificação morfossintática das expressões linguísticas) sofreria influência do Componente Contextual, codificando, dessa forma, diferentemente, as modalizações volitivas, conforme já proposto em Oliveira (2017). Para realizar a análise, propusemos algumas categorias relativas ao Componente Contextual com base em Hengeveld e Mackenzie (2008), Connolly (2014), Hengeveld e Mackenzie (2014) e Oliveira (2017), a partir das quais selecionamos quatro para a análise dos nossos dados.

Verificamos, nesta pesquisa, que houve uma maior ocorrência de modalizações volitivas em ambientes religiosos (53\% das ocorrências), sendo instauradas, preferencialmente, para o Ouvinte $2(52,1 \%$ das ocorrências). Verificamos, também, que o Componente Contextual inter-relaciona-se com o Nível Morfossintático ao influenciar as formas de expressão empregadas pelo Sumo Pontífice ao modalizar volitivamente, com predomínio de verbos plenos em ambientes políticos (19,7\% das ocorrências) e para instaurar modalizações volitivas para o Ouvinte 1 (20,5\% das ocorrências); e construções volitivas em ambientes religiosos ( $22,2 \%$ das ocorrências) e para expressar modalidade volitiva para o Ouvinte 2 ( $22,2 \%$ das ocorrências).

Tal resultado explica-se em razão da carga semântica dos verbos plenos, que asseveram a desejabilidade expressa em ambientes políticos e para o Ouvinte 1; enquanto as construções volitivas atenuam a desejabilidade expressa em razão de seu caráter desiderativo-apelativo (Grande Alija 2016), passando a funcionar como uma espécie de rogo ou súplica mais atenuada do que é desejado pelo Papa Francisco em ambientes religiosos e para o Ouvinte 2.

Ao fazermos uma análise qualititativa de outras duas categorias relacionadas ao Componente Contextual - o tipo de fenômeno abordado nos discurso do Papa Francisco (factuais ou não-factuais) e o tipo de relação estabelecida com os ouvintes (hierárquica ou não-hierárquica) - nos dados do corpus, verificamos que as modalizações volitivas apareceram relacionadas tanto a contextos factuais quanto a não-factuais e que o Papa Francisco parece 
projetar tanto um ethos de autoridade quanto um ethos de igualdade ao modalizar volitivamente.

\section{Referências bibliográficas}

Boaventura, Luis Henrique e Ernani Cesar de Freitas. 2016. A construção do ethos nos discursos do Papa Francisco, Gragoatá, 40: 317-338.

Camacho, Roberto Gomes e Eli Nazareth Bechara. 2011. Estratégias de relativização nas variedades lusófonas. Estudos Linguísticos, São Paulo, 40, 1: 183-195.

Catecismo da Igreja Católica. 2010. O Catecismo da Igreja Católica, São Paulo, Edições Loyola.

Connolly, John Hamilton. 2014. The contextual component within a dynamic implementation of the FDG model: structure and interaction, Pragmatics, 24, 2: 229-248.

Grande Alija, Francisco Javier. 2016. Imperativo, subjuntivo y el espacio desiderativo-apelativo, Círculo de Lingüística Aplicada a la Comunicación, 67: 167-211.

Hengeveld, Kees. 2004. Illocution, mood and modality, em Geert Booij, Christian Lehmann e Joachim Mugdan (eds.), Morphology: a handbook on inflection and word formation, Vol. 2, Berlin, Mouton de Gruyter: 11901202.

Hengeveld, Kees e John Lachlan Mackenzie. 2008. Functional Discourse Grammar: a typologically based theory of language structure. Oxford, Oxford University Press.

Hengeveld, Kees e John Lachlan Mackenzie. 2014. Grammar and context in Functional Discourse Grammar, Pragmatics, 24, 2: 203-227.

Maingueneau, Dominique. 1997. Novas Tendências em Análise do Discurso, Campinas/São Paulo, Pontes/Editora da Unicamp.

Oliveira, André Silva. 2017. Modalidade volitiva em língua espanhola nos discursos do Papa Francisco em viagem apostólica. Tese de mestrado, Universidade Federal do Ceará. Fortaleza. [em linha] Disponível em: http://www.repositorio.ufc.br/bitstream/riufc/28010/3/2017_dis_asoliveir a.pdf

Silva, Sandro Luis da. 2015. A homilia papal de 2014: congruência entre enunciação e ethos discursivo. Intersecções, 15, 1: 21-37.

NOTA:

ANDRÉ SILVA OLIVEIRA: A escrita do resumo e do abstract, bem como das palavras-chaves e das keywords. A elaboração da seção 2, sobre a interrelação entre o Componente Contextual e o Componente Gramatical dentro da GDF. A seleção das ocorrências que foram retiradas do córpus, a busca pela literatura necessária para embasar a análise empreendida. A escrita da seção referente aos resultados, análise e discussão dos dados, aliando os resultados encontrados ao arcabouço teórico tanto da GDF quanto de trabalhos correlatos à modalidade volitiva. 
NADJA PAULINO PESSOA PRATA: A correção do resumo e do abstract, bem como das palavras-chaves e das keywords. A escrita da introdução do artigo e das considerações finais. Em relação à seção de metodologia, elaborou as tabelas e dividiu com o autor a busca da literatura necessária para embasar as ocorrências encontradas no córpus. Elaborou as referências que foram postas no artigo.

SANDRA DENISE GASPARINI-BASTOS: A escrita da seção referente aos procedimentos metodológicos. Revisou a introdução e as considerações finais do artigo. Em relação à seção referente aos resultados e análise dos dados, revisou a parte teórica contida na análise no intuito de averiguar se havia alguma falha em relação à teoria da GDF e nos trabalhos referentes à modalidade volitiva. Após o término da escrita do artigo, colocou o artigo na formatação exigida pela revista. 